and died within 4-12 hr. No toxin was found in the neighbouring uninfected muscles of the same infected monkey.

$S$. kortei did not produce toxic manifestations when fed to laboratory rodents or when fed to, or inoculated into, rhesus monkeys. $S$. pitymysi did not produce toxic effects when injected intravenously into rabbits, or subcutaneously or intraperitoneally into rodents.

\title{
REFERENCES
}

Awad, F. I. . . . . . 1954. Ph.D. Thesis, Univ. London.

KNebel, M. . . . . . . . 1912. Zentbl. Bakt. ParasitKde, 66, 523.

Laveran, A., and Mesnil, F. . . 1899. C.r. Séanc. Soc. Biol., 51, 311.

Mandour, A. M. . . . . 1965. Ph.D. Thesis, Univ. London.

Mesnil, F., Chatton, E., ANd Pérard, C. 1913. C.r. Séanc. Soc. Biol., 75, 175.

PFEIfFER, L. . . . . . 1890. Die Protozoen als Krankheitserreger,

Rievel ANd Behrens . . . . . 1904. Zentbl. Bakt. ParasitKde, 35, 341.

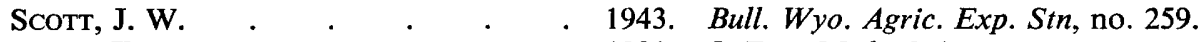

SмITH, T. . . . . . . $\quad$. 1901. J. Exp. Med., 6, 1.

Teichmann, E., and Braun, H. . . 1911. Arch. Protistenk., 22, 351.

\section{IDENTITY AND GLYCOGEN-FERMENTING ABILITY OF LACTO- BACILLI ISOLATED FROM THE VAGINA OF PREGNANT WOMEN}

\author{
Jean G. Wylie and A. Henderson \\ Research Department, Glasgow Royal Maternity Hospital, Rottenrow, Glasgow
}

DESPITE the appearance from time to time of evidence to the contrary, it is still widely thought that Lactobacillus acidophilus is the species of Lactobacillus most frequently found in the vagina in reproductive life, and that, by splitting glycogen, this organism causes the low $p \mathrm{H}$ found in the vagina. The matter is pursued further in this communication.

\section{MATERIALS AND METHODS}

Strains. Two series of cultures of lactobacilli were studied. (1) A series of authentic strains of 11 different species, 1 strain of each, was obtained from the National Collection of Industrial Bacteria (NCIB), the National Collection of Dairy Organisms (NCDO) and the National Collection of Type Cultures (NCTC). One strain was a holotype, 5 were cotypes and 9 were under consideration as the type strains of their species by the Lactobacillus Subcommittee of the International Committee on Bacteriological Nomenclature. These last 9 strains were: L. acidophilus NCIB8690, alternatively American Type Culture Collection (ATCC) no. 4356 (typical); L. buchneri NCIB8007 ( = ATCC4005) (typical); L. bulgaricus NCDO1489 (ATCC11842) (typical); L. casei NCDO161 (ATCC393) (cotype); L. cellobiosus NCDO928 (ATCC11739) (cotype); L. fermentum NCDO1750 (ATCC14931) (typical); L. lactis NCDO1438 (cotype); L. leichmannii NCIB7854 (ATCC4797) (typical); and L. salivarius NCDO929 (ATCC11741) (holotype). Also studied were L. brevis NCDO1749 (ATCC14869) (cotype) and L. helveticus NCIB8025 (ATCC8018) (cotype). (2) A series of 42 wild strains of Lactobacillus were obtained from the vagina of patients attending the Ante-Natal Clinic at the Glasgow Royal Maternity Hospital. Of these patients, 32 had no complaint or objective signs of discharge; a further group of 10 patients had a discharge due to infection with candida. 
The glycogen-fermenting strain of Corynebacterium diphtheriae NCTC3984 was used in control tests with the glycogen media.

Cultural and biochemical tests. The reconstituted contents of the ampoules of lyophilised cultures received from the collections and material from the swabs were spread on the agar described by de Man, Rogosa and Sharpe (1960). After incubation at $37^{\circ} \mathrm{C}$ in a jar containing air with 10 per cent. $\mathrm{CO}_{2}$, representative colonies were picked off into a broth of similar constitution without the agar (" lactobacillus broth", $p \mathrm{H} \mathrm{5.8).} \mathrm{After} \mathrm{further} \mathrm{in-}$ cubation, media were inoculated for the following tests. The strain's ability to grow at $22^{\circ} \mathrm{C}$ and $45^{\circ} \mathrm{C}$ in the lactobacillus broth was observed after 7 days' incubation at $37^{\circ} \mathrm{C}$. Its ability to grow in lactobacillus broth containing 2 or 6.5 per cent. sodium chloride $(\mathrm{w} / \mathrm{v})$ was observed. The production of acid from amygdalin, arabinose, cellobiose, galactose, glycogen, lactose, maltose, mannitol, melezitose, melibiose, raffinose, salicin, sorbitol, sucrose, trehalose and xylose was tested by culture in lactobacillus broth containing 2 per

\section{TABLE}

Species and glycogen-fermenting ability of 42 strains of Lactobacillus isolated from the vagina of pregnant women with or without vaginal discharge

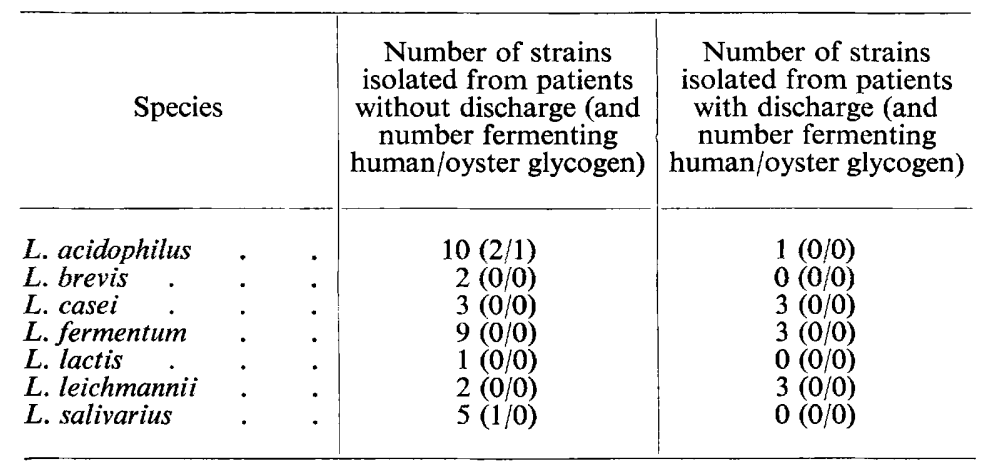

cent. (w/v) of the carbohydrate and 0.005 per cent. bromocresol purple for 7 days at $37^{\circ} \mathrm{C}$ in 10 per cent. $\mathrm{CO}_{2}$; no special steps were taken to remove the $\mathrm{CO}_{2}$ before reading. Production of ammonia from arginine was detected by the addition of Nessler's reagent to a 7-day-old culture in the medium of Niven, Smiley and Sherman (1943). The final identification was made according to the criteria of Cowan and Steel (1965).

Extraction of the vaginal glycogen. Fragments of human vagina were removed during repair operations. The tissue was placed immediately on ice. On arrival in the laboratory it was ground in a Teflon grinder under 10 per cent. (w/v) trichloracetic acid and the glycogen collected after overnight precipitation with ethyl alcohol as described by Roe et al. (1961). The concentrations of carbon, hydrogen and oxygen were assayed in a Coleman analyser by the Pregl method (Ingram, 1962) in the Department of Analysis, the University of Strathclyde, by kindness of Dr G. R. Proctor. The C:H ratio of the extracted vaginal glycogen was $38 \cdot 77: 5 \cdot 89$, as compared with the $\mathrm{C}: \mathrm{H}$ ratio of commercial oyster glycogen obtained from Messrs Hopkin and Williams Ltd, which was $38 \cdot 4: 5 \cdot 88$. It was noted that further purification of the glycogen by solution and re-precipitation altered the $\mathrm{C}: \mathrm{H}$ ratio to $43 \cdot 76: 6 \cdot 22$. The fermentation tests were therefore made with a sample of human vaginal glycogen that had not been purified by re-solution and re-precipitation. Absence of free glucose from this sample was demonstrated in a test with Benedict's reagent.

The glycogen was dissolved to a concentration of 2 per cent. in lactobacillus broth that contained bromocresol purple at a concentration of 0.005 per cent. and was free from other carbohydrates. The medium was sterilised by autoclaving at $121^{\circ} \mathrm{C}$ for $15 \mathrm{~min}$. The bacteria were inoculated and the culture was observed for the production of acid after 
7 days' incubation at $37^{\circ} \mathrm{C}$. Control tests were made with $C$. diphtheriae NCTC3984. Uninoculated tubes for comparison were not incubated.

\section{RESULTS}

Except in the tests for growth at $45^{\circ} \mathrm{C}$ and for fermentation of arabinose the 11 strains of Lactobacillus species obtained from the culture collections showed the reactions described for these species by Cowan and Steel. Six of the strains gave discrepant results in culture at $45^{\circ} \mathrm{C}$ and 6 gave discrepant results with arabinose. None of the 11 strains from the culture collections fermented oyster glycogen, but 3 of them, 2 of L. acidophilus (NCIB4504 and NCTC2949) and 1 of $L$. leichmannii (NCIB8117), fermented the preparation of human vaginal glycogen.

The identities of the 42 strains isolated from the vagina of pregnant women are shown in the table. Only 1 of the 11 wild strains of $L$. acidophilus produced acid from oyster glycogen, but 2 of them produced acid from human vaginal glycogen. None of the 31 wild strains of the other 6 species of Lactobacillus fermented oyster glycogen and only 1 of them (L. salivarius) fermented human vaginal glycogen.

\section{Discussion}

Cruickshank and Sharman (1934a and $b$ ) found copious glycogen in the vagina in the foetus and in the newborn infant up to the 3rd or 4th wk of life. Glycogen was then absent until the menarche, when it again became copious, particularly so in pregnancy, and persisted until the menopause. Lactobacilli made their appearance at $24-48 \mathrm{hr}$ after birth, but thereafter were found only in the presence of glycogen. Such findings led to the suggestion that the lactobacilli obtained energy by splitting the glycogen, the acid so produced inhibiting the growth of other species. However, Kienlin (1926) demonstrated the presence of acid in the infant's vagina before the appearance of lactobacilli, and Schröder, Hinrichs and Kessler (1926) suggested that the vaginal glycogen was first broken down to a simpler carbohydrate which was then metabolised by the lactobacilli. Rogosa and Sharpe (1960) studied 21 strains of Lactobacillus isolated from the vagina of healthy women who were not pregnant and identified 14 of them as L. acidophilus, 4 as L. fermentum, 2 as $L$. casei, and 1 as L. cellobiosus. They observed that no strain split glycogen in broth at $p \mathrm{H} 7 \cdot 0$, but some strains fermented it weakly in tests made in media with $p \mathrm{H}$ values of $5 \cdot 0,5 \cdot 8$ and 6.5 . Thus it seemed probable that these bacteria obtained their carbohydrate in the form of glucose split from glycogen, and possibly other carbohydrates, by the enzymes of vaginal tissue cells or by bacteria other than lactobacilli. Stewart-Tull (1964) made manometric observations on 36 strains of lactobacilli isolated from the vagina and cervix of ante-natal or post-natal patients and 6 strains from the intestine of breast-fed infants. Like Rogosa and Sharpe he concluded that vaginal lactobacilli could not initiate the breakdown of glycogen.

The papers cited above do not state the source of the glycogen; most batches of commercial glycogen are derived from oysters. When human glycogen was used in our own tests it was readily split by 4 strains of $L$. acidophilus, 1 of $L$. leichmannii and 1 of $L$. salivarius. These findings support the suggestion originally made by Cruickshank and Sharman that vaginal acidity is brought about, in part at least, by the vaginal lactobacilli.

\section{SUMMARY}

Thirty-two strains of lactobacilli were isolated from the healthy vaginas of pregnant women and 10 strains from the vaginas of pregnant women with a vaginal discharge due to candida infection. Of these 42 strains, 11 were Lactobacillus acidophilus, 2 were L. brevis, 6 were $L$. casei, 12 were $L$. fermentum, 1 was $L$. lactis, 5 were $L$. leichmannii, and 5 were $L$. salivarius. Whereas only 1 strain of $L$. acidophilus split oyster glycogen, human vaginal glycogen was split by 2 wild strains and 2 laboratory strains of L. acidophilus, 1 laboratory strain of $L$. leichmannii and 1 wild strain of $L$. salivarius. 


\title{
REFERENCES
}

Cowan, S. T., AND STEEL, K. J. . . . 1965. Manual for the identification of medical bacteria, Cambridge, p. 58.

Cruickshank, R., And Sharman, A. 1934a. J. Obstet. Gynaec. Br. Emp., 41, 190.

INGRAM, G. ." . . . . . . . . . . . . 1962. Methods of organic elemental micro-

KIENLIN, H. .

de Man, J. C., Rogosa, M., ANd Sharpe, 1960. J. Appl. Bact., 23, 130.

M. ELISABETH

Niven, C. F., JR, Smiley, K. L., AND 1943. J. Bact., 43, 651.

SHERMAN, J. M.

Roe, J. H., Bailey, J. M., Gray, R. R., 1961. J. Biol. Chem., 236, 1244. AND ROBINSON, J. N.

Rogosa, M., and Sharpe, M. Elisabeth 1960. J. Gen. Microbiol., 23, 197.

SCHRÖDER, R., HiNRICHS, R., AND 1926. Arch. Gynäk., 128, 94.

KESSLER, R.

STEWART-Tull, D. E. S. . . . . . 1964. Amer. J. Obstet. Gynec., 88, 676.

\section{NALIDIXIC ACID (NEGRAM) DISC TECHNIQUE FOR THE RAPID ISOLATION OF FAECAL STREPTOCOCCI FROM MIXED FLORA}

\author{
S. K. Devaraj and K. ZinnemanN \\ Department of Bacteriology, School of Medicine, Leeds
}

FAILURE of treatment of urinary infections due to faecal streptococci in association with other bacteria (Garrod, Shooter and Curwen, 1954) has indicated the need for combined antibiotic therapy in these cases (Eisenberg, Alexander and Flippin, 1953).

The incidence of streptococci in mixed urinary infections appears to vary from 10 per cent. (Sanford et al., 1956) to 22.4 per cent. (Rantz and Kirby, 1943). As could be expected, faecal streptococci were also found with coliform bacilli in gastro-intestinal perforation leading to peritonitis (Rantz and Kirby).

The difficulties of recovering faecal streptococci from a mixed flora have been noticed from time to time. Seidman, Ellis and Hill (1929) observed a lack of correlation between the smear and the culture of urinary sediments. Baker (1931) also noted that only Gramnegative organisms appeared in cultures although both Gram-positive and Gram-negative organisms were seen in smears. The possibility of suppression by the predominant organism has been suggested by Flint (1951) and Giertz and Gullbring (1951). Gould (1951) explained the discrepancy by the more rapid growth of the Gram-negative bacilli in a mixed urinary tract infection.

As streptococci (except occasional strains) are not inhibited by nalidixic acid in vitro, they can be isolated conveniently from the zones of inhibition of the coliform bacilli on primary culture plates.

\section{MATERIALS AND METHOD}

Media. (1) Nutrient agar. (2) MacConkey's agar, both for primary culture and isolation. (3) Five per cent. fresh horse blood agar plates for sensitivity tests.

Urine specimens. Centrifuged deposits of urine were examined by culture, and by wet and by Gram-stained preparations. One loopful of deposit was seeded on nutrient agar and MacConkey's agar, and incubated aerobically at $37^{\circ} \mathrm{C}$. 